\title{
Predictors of Spermatic Cord Torsion-Clinical Presentation and Intraoperative Findings
}

\author{
Axel Hegele $^{1^{*}}$, Dirk Wappelhorst ${ }^{{ }^{*}}$, Zoltan Varga ${ }^{2}$, Fabian Brüning ${ }^{1}$, Peter Olbert ${ }^{1}$, \\ Carsten Frohme ${ }^{1}$, Rainer Hofmann ${ }^{1}$ \\ ${ }^{1}$ Department of Urology and Pediatric Urology, University Medical Center, Marburg, Germany \\ ${ }^{2}$ Department of Urology and Pediatric Urology, Kreisklinikum Sigmaringen, Germany \\ E-mail: hegele@med.uni-marburg.de \\ Received July 21, 2011; revised August 30, 2011; accepted September 9, 2011
}

\begin{abstract}
Background: To evaluate aetiology of acute scrotum after surgical exploration suspicious for spermatic cord torsion, to compare surgical with clinical findings and to support the clinician distinguishing spermatic cord torsion from other diseases mimicking this emergency requiring surgical exploration. Methods: All men with the diagnosis of an acute scrotum who underwent emergency scrotal exploration between January 1995 and October 2009 were retrospectively evaluated. Results: 230 patients were analyzed. Torsion of the spermatic cord (53\%) was the most common cause followed by torsion of the testis appendages (25\%). Patients with spermatic cord torsion were significantly older $(15.5 \mathrm{y})$ and haunted hospital faster than others $(\mathrm{p}<0.001)$. Statistical analysis revealed that high testicular position and reduced/missing blood flow using duplex sonography are associated with increased probability of spermatic cord torsion. A significant difference in seasonal variation was not seen. Conclusions: Our data demonstrate that spermatic cord torsion is more common in adolescent. Short pain duration and high intrascrotal position of the testicle are associated with higher probability of spermatic cord torsion. Duplex sonography plays an important role in the diagnostic workup but history and physical examination are the crucial parameters. In nebulous clinical cases emergency surgical exploration has to be recommended.
\end{abstract}

Keywords: Acute Scrotum, Spermatic Cord Torsion, Emergency, Clinical Predictor

\section{Introduction}

Acute scrotum represents an emergency situation, that has to be diagnosed urgently. Also adequate therapy has to take place without loss of time $[1,2]$. An acute painful swelling of the scrotum is often accompanied with local signs like reddening and general symptoms. The reasons causing symptom complex of acute scrotum are manifold. A lot of differential diagnoses have to be taken into account: spermatic cord torsion, torsion of the appendages of testis, inflammatory diseases like acute epididymorchitis, incarcerated inguinal hernia or testicular tumors $[3,4]$. Among these diverse aetiologies spermatic cord torsion is of special clinical interest. Spermatic cord torsion mainly affects infants/juveniles and requires immediate surgical intervention [5]. The spermatic cord rotates in longitudinal axis so blood flow is completely or partially disabled. After $6 \mathrm{~h}$ of complete ischemia the testis is

\footnotetext{
"These authors contributed equally to this work.
}

irreversible damaged. Therefore, efficient and accurately diagnostic tools are essential for testicular salvage. In clinical routine medical history, carefully clinical evaluation and duplex sonography are performed. Physical examination is often not sufficient to form a diagnosis especially in infants. Duplex sonography is routinely used but if investigations are not confidently surgical exploration has to be performed following the principle "if in doubt check it out".

The aim of the present study was to evaluate aetiology of acute scrotum after surgical exploration suspicious for spermatic cord torsion, to compare surgical with clinical findings and to support the clinician distinguishing spermatic cord torsion from other diseases mimicking this emergency requiring surgical exploration.

\section{Patient and Methods}

All boys and men with the diagnosis of an acute scrotum 
clinically suspicious for spermatic cord torsion who underwent emergency scrotal exploration at the Department of Urology and Pediatric Urology (Medical Center, Philipps-University Marburg) between January 1995 and October 2009 were retrospectively reviewed.

Registered data included, beside medical history, demographic data like patient age, pain duration until haunting Department of Urology, affected side, swelling and actual season. Both physical findings like erythema of the scrotal region, tenderness of the scrotum, uplifted testis, testicular and/or epididymal pain and results of preoperatively performed duplex sonography were recorded.

Statistical analyses were performed using the nonparametric Mann-Whitney U-test to compare the results between different groups. The Kruskal-Wallis ANOVA test was used to analyze the differences between the different groups and subgroups (Statistical Packages for Social Sciences SPSS ${ }^{\circledR}$ for Windows, Version 17). Statistically significance was accepted when p-value reached $<0.05$.

\section{Results}

In the mentioned time period a total of 237 men clinically suspect for spermatic cord torsion were surgically explored at the Department of Urology and Pediatric Urology. 230 patients were evaluable (median age 12.5 years, range 1 day - 46 years).

All patients suffered testicular pain. Torsion of the spermatic cord was the most common cause of acute scrotum found in 122 patients (Group A: 53\%), followed by torsion of the testis appendages in 58 patients (Group B: $25 \%$ ), acute epididym-orchitis in 29 patients (Group C: 13\%) and other aetiologies in 21 patients (Group D: 9\%).

Patients with spermatic cord torsion (mean age 15.5 years, range 1 day - 43 years) were significantly older than patients of Group B-D ( $<0.001$, Figure 1).

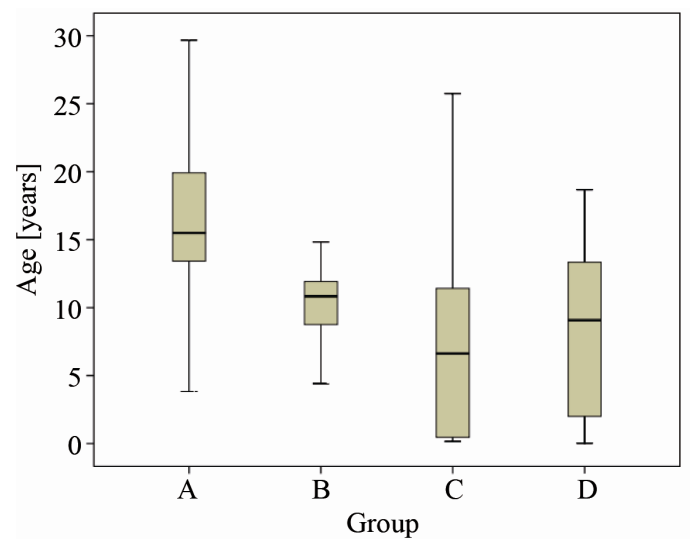

Figure 1. Mean age of patients Group A - D $(\mathbf{p}<0.001)$.
Patients with acute epididym-orchitis (Group C) displayed the youngest age group (mean 6.9 years, range 2 months - 46 years).

Side location showed no significant differences: right testis was affected in 104 (45.2\%) and left testis in 126 patients (54.8\%).

Group A had mean symptom duration until haunting hospital of $6 \mathrm{~h}$ (SD $\pm 114 \mathrm{~h}$, range 1 - 28 days). No statistical significant differences were found concerning left or right side (53.3\% vs. $46.7 \%$ ). Swelling and reddening of the scrotal area were documented in $77.1 \%$ of the patients. Scrotal uplifted testicle was found in $78 \%$ of the cases. Duplex sonography revealed decreased or absent blood flow in $54 \%$.

Group B haunted hospital after 24h of painful symptoms (SD $\pm 35 \mathrm{~h}$, range $1 \mathrm{~h}-6.2$ days). Left side was affected in $58.6 \%$ of the cases. Swelling and reddening were seen in $71 \%$ of the cases, uplifted testicle was found in 32\% and duplex sonography showed no or limited testis perfusion in $19 \%$.

Group C came to hospital after mean symptom duration of $24 \mathrm{~h}$ (SD $\pm 22 \mathrm{~h}$, range $3.5 \mathrm{~h}-4$ days), presenting swelling and reddening in $97 \%$, uplifted testicle in $19 \%$ and abnormal testicular blood flow in $17 \%$ of the cases. Right side was affected in $55.2 \%$ of the patients.

Group D had mean symptom duration of $10 \mathrm{~h}$ (SD \pm $20.1 \mathrm{~h}$, range $1.5 \mathrm{~h}-3$ days), showing swelling and reddening in $70 \%$, uplifted testicle in $18 \%$ and suspicious duplex sonography in $20 \%$. Left side was affected in about two third of the cases (66.7\% vs. $33.3 \%$ ).

Statistical analysis revealed that high testicular position is common in torsion of the spermatic cord with significant difference compared to other aetiologies causing acute scrotum $(\mathrm{p}<0.001)$. Swelling and reddening showed no significant differences between the different groups $(\mathrm{p}=0.071)$. Duplex sonography revealed significant reduced or totally missing testicular blood flow in spermatic cord torsion compared to other aetiologies $(\mathrm{p}=$ 0.015 ). Additionally, patients with spermatic cord torsion haunted hospital significant faster than others ( $\mathrm{p}<0.001$, Figure 2). No significant difference of affected side location was detectable in the investigated cohort and the subgroups. Patient characteristics, presented symptoms and clinical findings of the different groups are summarized in Table 1.

A significant difference in seasonal variation was not seen: highest number of patients with acute scrotum and need of emergency surgical intervention were found in spring $(n=63)$ compared to summer, fall and winter $(n=$ $56, n=58, n=53$ resp.). Also no significant seasonal differences were detectable within Group A-D (Figure 3). 
Table 1. Patient characteristics separated concerning intra-operative findings (Group A: spermatic cord torsion, Group B: torsion of the testis appendages, Group C: acute epididym-orchitis, Group D: others).

\begin{tabular}{cccccccccc}
\hline & Number & $\begin{array}{c}\text { Median age } \\
\text { (years) }\end{array}$ & $\begin{array}{c}\text { Median time dura- } \\
\text { tion (h } \pm \text { SD) }\end{array}$ & \multicolumn{2}{c}{ Affected side } & High testicular & $\begin{array}{c}\text { Swelling/ } \\
\text { position }\end{array}$ & $\begin{array}{c}\text { Sonography } \\
\text { reddening } \\
\text { (no/reduced } \\
\text { blood flow) }\end{array}$ \\
\hline Group A & 122 & 15.5 & $6(114)$ & 57 & 65 & $77.9 \%$ & $77.1 \%$ & $54.4 \%$ \\
Group B & 58 & 10.8 & $24(34.8)$ & 24 & 34 & $31.8 \%$ & $71.2 \%$ & $19.1 \%$ \\
Group C & 29 & 6.9 & $24(21.8)$ & 16 & 13 & $19 \%$ & $96.6 \%$ & $16.7 \%$ \\
Group D & 21 & 9.1 & $10(20.1)$ & 7 & 14 & $16 \%$ & $65.1 \%$ & $12,1 \%$ \\
total & 230 & 12.7 & & 104 & 126 & & & &
\end{tabular}

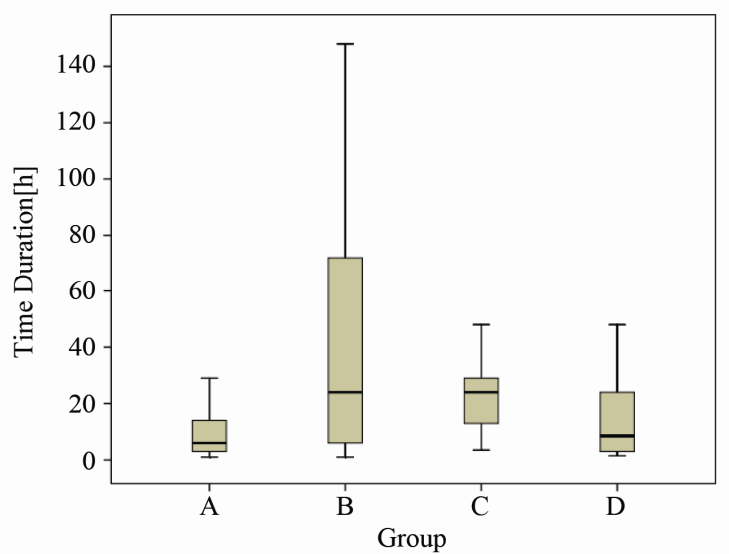

Figure 2. Median time duration of pain until haunting hospital $(\mathrm{p}<\mathbf{0 . 0 0 1})$.

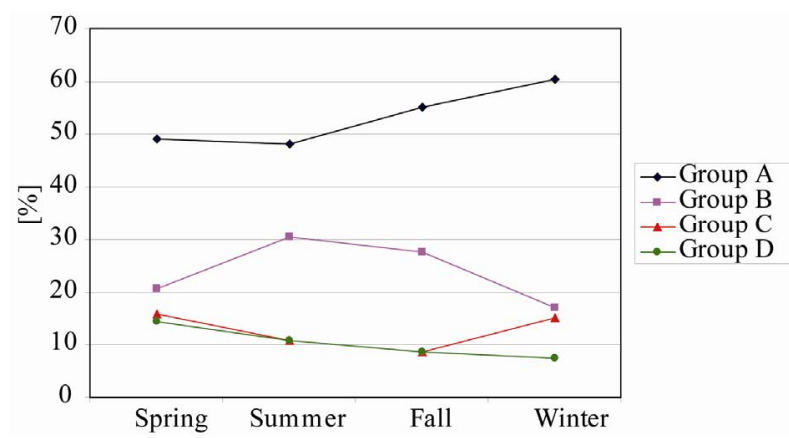

Figure 3. No seasonal significant variation was seen between and within the different aetiologies causing acute scrotum.

\section{Discussion}

Acute scrotum represents one of the most difficult situations for the clinician. Especially spermatic cord torsion, showing an incidence about 1:4000, is utmost importance. Delay of diagnosis and inadequate therapy may result in loss of the testis. In view of manifold differential aetiologies causing an acute scrotum, despite careful clinical evaluation and lack of time surgical exploration will be performed in cases suspicious for spermatic cord torsion [1,2]. Thus, some patients will be operated although their disease could be treated conservatively. We present our findings in 230 patients undergoing surgical exploration to exclude spermatic cord torsion after clinical evaluation. In our large cohort spermatic cord torsion was most common in $53 \%$ of patients, followed by torsion of the testicular appendages in $25 \%$ and epididym-orchitis in $13 \%$. Hegarty and co-workers presented similar data of 100 patients finding spermatic cord torsion most common (33\%) [6]. Cavusoglu et al. found spermatic cord torsion only in $29 \%$ but epididym-orchitis in $37 \%$ of 165 surgically explored patients. Additionally they reported that in neonatal period the most common pathology was spermatic cord torsion and in prepubertal period torsion of the appendages [7]. In contrast our data of 230 consecutive patients showed that epididym-orchitis was most common in younger age group (median 6.9 years), patients suffering spermatic cord torsion were significantly older (median 15.5 years). An explanation for this findings maybe the ability of the older patients to tell anamnestic details concerning typical clinical features: i.e. sudden-onset pain in spermatic cord torsion.

Our findings were supported by data of Ben-Chaim and co-workers. In $70 \%$ of 171 patients spermatic cord torsion was present. Dividing their examined population concerning age spermatic cord torsion was most common found in adults, followed by adolescents and children (88\%, 86\% and 34\%, respectively) indicating the importance of a detailed anamnesis and the ability of the patients to tell typical clinical features [8]. Similar data were published by Beni-Israel and co-workers from a pediatric emergency department. Out of 523 patients with a mean age of 10 years and 9 months presenting an acute scrotum only $3.25 \%$ suffered spermatic cord torsion [9]. Furthermore, our data concerning clinical predictors for spermatic cord torsion reveal that the uplifted 
testicle is significantly more existent in spermatic cord torsion compared to other painful entities causing acute scrotum. Additionally, patients with spermatic cord torsion haunted hospital significantly faster. Other clinical signs like reddening and swelling seem not to be sufficiently reliable. Our clinical predictors associated with higher likelihood of spermatic cord torsion are in line with others $[3,9,10,11]$. These authors described also that high position of testicle and short time duration until haunting hospital are associated with existence of spermatic cord torsion.

Our data underline the impact of duplex sonography in this emergency situation and in the diagnostic workup of acute scrotum $[1,12,13]$. In our large cohort we found significant reduction or loss of testicular perfusion in spermatic cord torsion. However, the performance and interpretation are operator-dependent and are supported by history and physical findings thus in clinical unclear cases surgical exploration is still indicated [14]. Some authors described a seasonal variation of spermatic cord torsion incidence. Lyronis and co-workers described a significant increased appearance of spermatic cord torsion during greek winter in 140 boys [15]. Srinivasan and co-workers found, using multivariate analysis, a significant correlation between spermatic cord torsion and decreasing atmospheric temperature in 58 US children [16]. Malakindiah and co-workers described an increased occurrence from October to March in India [17]. Williams and co-workers did not see statistical relevant differences between the different seasons but they also described a trend to winter [18]. Our data showed that patients with acute scrotum are most common in spring. Concerning spermatic cord torsion we found no signifycant seasonal differences, suggesting no aetiological role for climatic conditions especially decreasing temperature in Germany. These different findings maybe explained by the different locations Greek, US, India and Germany.

\section{Conclusions}

In conclusion our data demonstrate that in over $50 \%$ of patient suffering an acute scrotum and demand for emergency surgical exploration spermatic cord torsion was found. Additionally spermatic cord torsion is more common in adolescent. Short pain duration until haunting hospital and high intrascrotal uplifted position of the testicle are associated with higher probability of a spermatic cord torsion. A seasonal variation in the incidence of acute scrotum and especially spermatic cord torsion with parallelism to decreasing temperature was not seen. Duplex sonography plays an important role in the diagnostic workup but history and physical examination are the crucial parameters in aetiology evaluation of an acute scrotum. Therefore differential diagnosis of acute scrotum still remains a diagnostic challenge. Our data underline that in any case suspicious for spermatic cord torsion emergency surgical exploration has to be performed immediately.

\section{References}

[1] M. Baldisserotto, "Scrotal Emergencies," Pediatric Radiology, Vol. 39, No. 5, 2009, pp. 516-521. doi:10.1007/s00247-008-1134-0

[2] J. M. Gatti and J. Patrick Murphy, "Current Management of the Acute Scrotum," Seminars in Pediatric Surgery, Vol. 16, No. 1, 2007, pp. 58-63. doi:10.1053/j.sempedsurg.2006.10.008

[3] A. O. Ciftci, M. E. Senocak, F. C. Tanyel and N. Büyükpamukçu, "Clinical Predictors for Differential Diagnosis of Acute Scrotum," European Journal of Pediatric Surgery, Vol. 14, No. 5, 2004, pp. 333-338. doi:10.1055/s-2004-821210

[4] E. Somekh, A. Gorenstein and F. Serour, "Acute Epididymitis in Boys: Evidence of Post-Infectious Etiology," Journal of Urology, Vol. 171, No. 1, 2004, pp. 391-394. doi:10.1097/01.ju.0000102160.55494.1f

[5] H. F. McAndrew, R. Pemberton, C. S. Kikiros and I. Gollow, "The Incidence and Investigation of Acute Scrotal Problems in Children,” Pediatric Surgery International, Vol. 18, 2022, pp. 435-437.

[6] P. K. Hegarty, E. Walsh amd M. O. Corcoran, "Exploration of the Acute Scrotum: A Retrospective Analysis of 100 Consecutive Cases,” Irish Journal of Medical Sciences, Vol. 170, No. 3, 2001, pp. 181-182. doi:10.1007/BF03173885

[7] Y. H. Cavusoglu, A. Karaman, I. Karaman, D. Erdogan, M. K. Aslan, O. Varlikli and O. Cakmak, “Acut ScrotumEtiology and Management,” Indian Journal of Pediatrics, Vol. 72, No. 3, 2005, pp. 201-203. doi:10.1007/BF02859255

[8] J. Ben-Chaim, I. Leibovitch, J. Ramon, D. Winberg and B. Goldwasser, "Etiology of Acute Scrotum at Surgical Exploration in Children, Adolescents and Adults," European Urology, Vol. 21, 1992, pp. 45-47.

[9] T. Beni-Israel, M. Goldman, S. Bar Chaim and E. Kozer, "Clinical Predictors for Testicular Torsion Seen in the Pediatric ED," American Journal of Emergency Medicine, Vol. 28, No. 7, 2010, pp. 786-789. doi:10.1016/j.ajem.2009.03.025

[10] I. Mushtaq, M. Fung and M. J. Glasson, "Retrospective Review of Paediatric Patients with Acute Scrotum," ANZ Journal of Surgery, Vol. 73, No. 1-2, 2003, pp. 55-58. doi:10.1046/j.1445-2197.2003.02612.x

[11] G. Soccorso, G. K. Ninan, A. Rajimwale and S. Nour, "Acute Scrotum: Is Scrotal Exploration the Best Management?” European Journal of Pediatric Surgery, Vol. 20, No. 5, 2010, pp. 312-315. doi:10.1055/s-0030-1254150 
[12] P. Gunther, J. P. Schenk, R. Wunsch, S. Holland-Cunz, U. Kessler, J. Trogera and K. L. Waag, “Acute Testicular Torsion in Children: The Role of Sonography in the Diagnostic Workup,” European Radiology, Vol. 16, No. 11, 2006, pp. 2527-2532. doi:10.1007/s00330-006-0287-1

[13] P. Pavlica and L. Barozzi, "Imaging of the Acute Scrotum,” European Radiology, Vol. 11, No. 2, 2001, pp. 220228. doi:10.1007/s003300000604

[14] P. Pepe, P. Panella, M. Pennisi and F. Aragona, "Does Color Doppler Sonography Improve the Clinical Assessment of Patients with Acute Scrotum?” European Journal of Radiology, Vol. 60, No. 1, 2006, pp. 120-124. doi:10.1016/j.ejrad.2006.04.016

[15] I. D. Lyronis, N. Ploumis, I. Vlahakis and G. Charissis, "Acute Scrotum-Etiology, Clinical Presentation and Sea- sonal Variation,” Indian Journal of Pediatrics, Vol. 76, 2009, pp. 407-410.

[16] A. K. Srinivasan, J. Freyle, J. S. Gitlin and L. S. Palmer, "Climatic Conditions and the Risk of Testicular Torsion in Adolescent Males," Journal of Urology, Vol. 178, No. 6, 2007, pp. 2585-2588. doi:10.1016/j.juro.2007.08.049

[17] G. C. Malakindiah, R. K. Jindal and S. Vaidyanathan, "Seasonal Variation in the Occurrence of Testicular Torsion at Chandigarh, India,” Indian Journal of Urology, Vol. 2, 1986, pp. 69-72.

[18] C. R. Williams, K. J. Heaven and D. B. Joseph, “Testicular Torsion: Is There a Seasonal Predilection for Occurrence?” Urology, Vol. 61, No. 3, 2003, pp. 638-641. doi:10.1016/S0090-4295(02)02498-6 